\title{
NOVELA CORTESANA, NOVELA BARROCA, NOVELA CORTA: DE LA INCERTIDUMBRE AL CANON
}

\author{
EVANGELINA RodRíGuEZ CUADRos \\ Universitat de València \\ evangelina.rodriguez@uv.es \\ Blog Ars Theatrica: http://parnaseo2.uv.es/blogtheatrica/
}

L

a experiencia de escribir una tesis doctoral —lo pienso ahora cuando tal género va extinguiéndose en la algarabía burocrática que oxida la universidad - señala un destino intelectual: aunque la vida académica (que es también creación) acabe llevándote a otros territorios, existirá siempre una oportunidad de retorno. A veces, muy temprano. Todavía recuerdo cuando en 1978, inmaculadamente mecanografiada y encuadernada la mía, que titulé (lo que ahora reconozco como torpe profecía) Novela corta marginada del siglo XVII español, encontré ese artículo suelto que fatídicamente siempre se escapa en la bibliografía. Se trataba, en este caso, de «Problemática de la novela corta» de René Etiemble (1909-2002), dentro de sus Ensayos de literatura (verdaderamente) general (1977: 127-137). Descubrí que podía haber elegido otros muchos nombres para engolar mi investigación sin haberme atenido a novela, un étimo del que nadie con más gracia que Juan Timoneda había hecho etimología en su Patrañuelo de 1565¹. El género se extendía a un nomenclátor tan esotérico como novella, nouvelle, histoire, monogatari, kaiskaz, erzählung, conte, short story, novelette, Kurzgeschichte, o tjerpen ${ }^{2}$. Pero Etiemble no recordaba que nuestra María de Zayas ya había reclamado, en 1638, llamar a las suyas maravillas, pues «con este nombre quiso desembarazar al vulgo del de novelas, título tan enfadoso que ya en todas partes aborrecen». El lúcido comparatista sí sacaba a colación, sin embargo, la

1 «Patraña no es otra cosa que una fengida traza, tan lindamente amplificada y compuesta, que parece que trae alguna apariencia de verdad. Y así, semejantes marañas las intitula mi lengua natural valenciana, Rondalles, y la toscana: Novelas, que quiere decir: “Tú, trabajador, pues no velas, yo te desvelaré con algunos graciosos y asesados cuentos, con tal que los sepas contar como aquí van relatados”». Véase Timoneda (1971: 41).

2 Anteriormente había debatido sobre esta terminología Gillespie (1967: 117-127). 
nota de Paul Scarron en Le Roman Comique (1651): «Los españoles poseían el secreto de inventar pequeñas historias, que ellos llaman novelas, que van mejor en nuestros usos y están más al alcance de la humanidad que los héroes imaginarios de la Antigüedad». No estaba mal para una época en la que su país hacía desfilar por los escenarios, en heroica elocuencia de alejandrinos, toda la estirpe mitológica, desde Edipo a Mitrídates y desde Ifigenia a Fedra. Por entonces los españoles se las veían más bien, en la triunfante comedia nueva, no sólo con una aristocracia señorial sino también con una nobleza urbana (a veces de medio pelo) que disfrutaba de su reflejo en las tablas. Pero no ya sólo en ellas. Porque, entre 1635 y 1665, ya se habían editado casi un $47 \%$ de las numerosas colecciones de aquellas novelas cortas $^{3}$, convertidas en una alternativa de voraz consumo a lo que se ofrecía en los corrales. Nos lo recuerda Juan de Zabaleta (1983: 387) en su Día de fiesta por mañana (1663), donde describe a una mujer, en su casa, absorta en «esas que llaman novelas [...], porque en esta lectura el principio hace gana incorregible de llegar al fin [...], que hablan con agrado y utilidad a la oreja del corazón», advirtiendo que «no mueve ni embravece tanto los afectos como la comedia, porque habla como que cuenta y no como que padece». La cita nos propone, sin lugar a dudas, la existencia de una cultura privada - decisiva en la evolución de la sociedad europea entre los siglos XVI y XVII — frente al rito colectivo del teatro ${ }^{4}$; una cultura literaria en la que sería infrecuente - pero no imposible- la creación de situaciones más propicias a transgredir el hegemónico asentimiento a la moral tridentina; ésta, por mucho que se haya insistido en lo contrario, apretaba (pero no siempre ahogaba) a aquellos relatos bebidos, como muestra Zabaleta, en el teatralizado fervor de la imaginación.

Mi segundo retorno a la novela corta — todavía oficialmente cortesana según la circunspecta historiografía - sucedió en 1983, leyendo casualmente un artículo publicado por Gabriel García Márquez en El País (23 de febrero: 9) bajo el título «Historias perdidas». El gran forjador de novelas cortas (y largas) se refería al interés que le había despertado conocer que el argumento del célebre drama de Albert Camus Le malentendu (1944) — a saber, el trágico regreso de Jan, años después de su partida, al hotel regentado por sus padres quienes, sin reconocerlo, lo asesinan para robarle el dinero - era una variante de una historia transmitida por la tradición oral desde la Edad Media; y era, además, harto probable que Camus se inspirara también en una intriga policíaca acaecida en Tours en 1796; su acción, por fin, reproducía la de una tragedia de Zacarías Werner (1768-1823) llamada El 24 de febrero. Me quedé perpleja: porque era exactamente el caso con que se

\footnotetext{
Lo contabilizó Pacheco-Ransanz (1986: 412). La adscripción del género a la autocelebración aristocrática fue señalada hace años por Martínez Camino (1976: 33-47).

4 De lo que dieron cuenta Morínigo (1957: 8-76), Yudin (1966: 585-94) o Baquero Goyanes (1983: II, 13-19).
} 
cerraba una de las más truculentas novelas insertas por José Camerino — uno de los autores objeto de mi tesis - en sus Novelas amorosas (1624): en El amante desleal don Fadrique, abandonando a su suerte a Aurora con la que tiempo atrás se había fugado, regresa a su Valencia natal con el botín de joyas y monedas que le ha sustraído; decide alojarse, sin revelar su identidad, en su propia casa y sus padres, para desvalijarlo, lo asesinan mientras duerme.

Reconfortada por el brevísimo guiño de tradición y modernidad que, sin saberlo, había alojado mi tesis — convertida en libro en 1979—, tuve la osadía de proponer la edición de una antología de aquellas novelas, la mayoría aún sepultadas en la tacaña selección de los tomos de Novelistas posteriores a Cervantes de la Biblioteca de Autores Españoles, en emotivas ediciones de Emilio Cotarelo o en raras colecciones de bibliófilo. A la postre, en mis Novelas amorosas de diversos ingenios del siglo XVII (tal fue el título impuesto por los editores frente a mi preferencia por el de Intercadencias de la calentura de amor — una sabrosa summa de las calamidades del eros secreto- publicadas en 1685), opté por homenajear a Camerino tanto en la melodramática Los efectos de la fuerza como en el inofensivo paseo por la farándula y dulzona versión del Buscón quevediano de El pícaro amante que, a su vez, había encandilado, casi hasta el plagio, a Pierre de la Geneste en su peculiar adaptación L'Aventurier Buscon (1633). Desde luego, no me sustraje a incluir obras como La mayor confusión de Juan Pérez de Montalbán (con un tirabuzón de incestos que sortearon asombrosamente la censura hasta ediciones muy posteriores), de sus Sucesos y prodigios de amor en ocho novelas ejemplares (1624); la no menos tremebunda Los hermanos amantes de Luis de Guevara (autor de las citadas Intercadencias); La industria vence desdenes de las impagables Navidades en Madrid (1663) de Mariana de Carvajal, quien, ya en la viudez encontró su «habitación propia» de escritora para sacar adelante a su prole; la extravagante Los dos soles de Toledo de Alonso Alcalá y Herrera (dentro Varios effetos de amor de 1641 - y escrita, de acuerdo con el virtuosismo barroco del lipograma - sin la vocal a) $)^{5}$; La fantasma de Valencia de Cristóbal Castillo Solórzano, incluida, en su azaroso quehacer de autor de pane lucrando, en sus Tardes entretenidas (1625); y, finalmente, el remedo de la cofradía de Monipodio cervantino que perpetrara Andrés de Prado (otro autor que analicé en mi tesis) en Ardid de la pobreza y astucias de Vireno, de Meriendas del ingenio y entretenimientos del gusto (1663). Ocho (y no doce, el número consagrado por Cervantes en las Novelas ejemplares reunidas en 1613): mi afán ecléctico - dentro de la variable calentura prerromántica de los amores prohibidos_-intentaba constatar lo mucho que aún faltaba para una objetiva valoración de un género más lábil (pero menos letal) de lo que la crítica había dado a entender hasta entonces y para el que, a

5 Técnica brillantemente estudiada después por Gallo (2003).

Edad de Oro, XXXIII (2014), pp. 9-20, ISSN: 0212-0429 
despecho del sentido lukacsiano del héroe de la novela moderna, no se había encontrado otro marbete oficial alternativo al del benemérito Agustín González de Amezúa (1951: I, 194-279) en su estudio «Formación y elementos de la novela cortesana». Esta narrativa tuvo, desde luego, la mala suerte de ser excluida del canon nacional que había consagrado el Manual de literatura española de Antonio Gil de Zárate (1844), cuya desidia pasó por llamar a El caballero puntual de Salas Barbadillo, El caballero del Puntal, o a Las harpías en Madrid de Castillo Solórzano, La Sarpia en Madrid. Con mi edición intenté asimismo atender a la evidencia de que había vida más allá y acá de las ejemplares — en todos los sentidosnovelas cervantinas. Señaló el camino Edwin B. Place en su Manual elemental de Novelística Española. Bosquejo histórico de la novela corta y el cuento durante el Siglo de Oro con tablas cronológico-descriptivas de la novelística desde los orígenes hasta 1700, libro de 1926 cuyo título era casi más largo que el propio ensayo; y The Short Story in Spain in the Seventeenth Century de la hispanista Caroline B. Bourland (1927), que incluía una bibliografía de su producción entre 1576 y 1700. La pléyade de obras sometidas (en unos casos, que no en todos) al esquema decameroniano o al naufragio costumbrista y pseudo-picaresco, me ratificaba en la opinión que, desde mi tesis, me atreví a sustentar: que la historia global de la novela española del siglo Xvir estaba aún por hacer.

En esas estaba cuando se publicó en 1991 el muy completo catálogo bio-bibliográfico La novela barroca (1620-1700) de Begoña Ripoll (1991: 18-19), lo que provocó mi tercer regreso a la cuestión. Hablaba la autora de mis «rígidas conclusiones», pues —añadía — «no ha estudiado ninguna novela larga del siglo XVII» y «nos resulta paradójico que pretenda comparar las Novelas amorosas de Camerino y las Meriendas del ingenio de Andrés de Prado». Concluyendo que «parece ignorar la gran relación que existe, conforme transcurre el siglo, entre el creciente auge del género de entretenimiento y la solución estructural adoptada por los escritores que intentan moralizar más explícitamente con estas obras, que no es sino intensificar los elementos argumentales, retóricos y estilísticos que pueblan las novelas para aumentar el número de páginas y, así, dar satisfacción a la demanda del público lector». El catálogo de Ripoll no acogía una sola novela más extensa que las que yo había estudiado o editado (desde luego solo de siete autores de entre los treinta y dos que ella había inventariado, pero los siete ofrecían ya una palpable variedad de tonos y marcos estructurales). No obstante, me dispuse a reflexionar con sincera anagnórisis sobre todo lo hecho; y, en un artículo de 1996 y una edición de 1999, en colaboración con Marta Haro, me ratifiqué - ya con más cautela - en lo que ahora revela el creciente vigor de la investigación sobre este tipo de novelas: que no todo estaba dicho ni acaso todo lo bien que podría haberse dicho, pero el modesto borrador con el que me las tuve que ver para amueblar el edificio de un género — al que sólo Pilar Palomo (1976) 
había aplicado nomenclaturas de ensarte y función, sistema y universo representado- era ya, en vísperas de un nuevo siglo, un mapa legible, adentrado por fin en una especulación filológica moderna. Y es que el foco de interés que Giovanna de Gregorio Formichi (1973) había centrado en las causas de su producción masiva - luego que Cervantes demostrara que eran más productivas, editorialmente hablando, liberadas del marco narrativo boccaciano o similares- llevó pronto a la aplicación de una semiótica pragmática en la que el signo novela corta ya no era sólo un vagaroso brujulear por su genealogía o un híbrido querer y no poder entre el costumbrismo y la idealización aristocrática, sino algo que significó algo para alguien en un momento en que «el contexto real socializado», como escribió Jenaro Talens (1977: 121-181), inventaba, y cómo, nuevos espacios en los que la quinta florentina de Boccaccio se transformaba en saraos, carnavales, navidades, huertas, jardines, cigarrales, meriendas y hasta mojigangas del gusto (dudoso gusto, sí, el de Andrés Sanz del Castillo, que rotuló así su colección de 1641).

Se había precisado un nuevo objeto de consumo kitsch — pues Maravall hacía furor con La cultura del barroco desde 1975-. No importaba que Lope escribiera picado con Cervantes o que subrogara, por muchos «intercolumnios» y mucha narrativa «científica» que se inventara para ilustrar a Marta de Nevares en sus Novelas a Marcia Leonarda, los preceptos del teatro y la novela a la libertad subjetiva del gusto. Lo cierto era que el canon del gusto, establecido en competencia con el teatro, nos proveía de un nuevo espacio donde discernir en el Siglo de Oro el atisbo de modernidad — pues lo era — de una literatura que no intentaba, aunque sus primeros críticos (y otros postreros) se empeñaran en ello, la verdad objetiva sino, acaso, el fresco de la república de hombres encantados que fue el siglo xviI, donde se mezclaban nobleza desteñida, hidalgos urbanos, estudiantes sopistas, torpes rufianes, héroes y heroínas traídos y llevados por viajes bizantinos ${ }^{6}$, cautivos y cautivas en el desesperado trance de elegir entre la fidelidad a sus amados o amadas o a sus captores turquescos o moriscos; y hasta mancebos con vocación de vestales masculinos, ninfas aguerridas y sátiros merodeando en la mítica Creta. Sus autores, con mayor o menor habilidad, aglutinaban lo que un ávido público lector buscaba: no solo la idea de lo que aquella sociedad se hacía sobre sí misma, sino un mundo abreviado de todo lo que el arte de narrar había ensayado, de algún modo, hasta ese momento. Eran - aparte de la servidumbre a la moral tridentina y a un cansino festón edificante (casi siempre como de compromiso final) - la herencia definitivamente profana y laica, siempre pespunteada de alardes poéticos, del complejo magma de la narración breve diletante entre los exempla religiosos, los nova morales y el cuento folclórico que habían analizado brillantemente Walter

$6 \quad$ Sobre esta querencia bizantina por el viaje, véase Barella (1994: 203-222). Y sobre el diletantismo del gusto nazarí del cautiverio, el trabajo de mi inolvidable amiga Soledad Carrasco Urgoiti (1995: 47-69). 
Pabst (1972) y Wolfram Krömer (1979). Y la entrega a lo «peregrino y ejemplar» (por recordar las historias recopiladas por Gonzalo de Céspedes y Meneses en 1623) se barajó con la incisiva tragicidad de algunas historias remotamente bandellianas, como las citadas La mayor confusión y Los hermanos amantes. Desde la perspectiva del puro entretenimiento, y pese a su vocación oral sostenida en el relato enmarcado en una reunión, suponían también la primera oportunidad del lector para sustraerse a la comunidad que lo envolvía y, como consecuencia, la interiorización inmediata de lo leído por quien lo lee (remito a mi referencia anterior a Juan de Zabaleta). Todo ello con la creación definitiva del concepto de habitus que Pierre Bourdieu otorga a la capacidad de una sociedad de elegir libremente qué leer con el fin de ocupar el ocio y, con ello, la creación de los esquemas con los que los sujetos perciben el mundo y desean o sueñan actuar en él. Desde luego la novela corta del Barroco define, a su modo, una estética; define no una, sino múltiples ópticas lectoras en su propio contexto; y define, aunque sea borrosamente - y no es casualidad que lo haga casi en paralelo a la comedia del mismo periodo-, la fascinante dialéctica entre el valor de uso y el valor de cambio de un producto cultural. El «se compran, se buscan y apetecen» de Tirso de Molina en la introducción a su Deleitar aprovechando (1635), es, si se me permite, una tardía trasposición del juicio cervantino sobre el teatro de su tiempo como «mercadería vendible» (Quijote, I, 48) confirmada en los sarcásticos versos de Lope en los versos 47-48 de su Arte nuevo de hacer comedias de 1609: «porque como las paga el vulgo es justo / hablarle en necio para darle gusto». Por demás está decir que los tres se empeñaron en trascender, con la genialidad de la que carecieron otros escribidores del siglo, el mero valor de cambio, sabiendo que su producción novelesca iba a sobrevivir a las clasificaciones neoaristotélicas de su tiempo, gracias a una pujante poética no escrita y a una nueva conciencia del existir, menesterosa de géneros nuevos.

Entre los años ochenta y noventa del ya siglo pasado y los inicios de éste, la novela corta acaricia la posibilidad de un nuevo y específico canon de estudio. Académicamente hablando lo había hecho gracias a González de Amezúa (a fin de cuentas el estudio citado fue su discurso de entrada en la Real Academia en 1929). Pero va dejando atrás su anclaje exclusivo en el paisaje cortesano. Y aunque en 1983 sigue castigada a la minoridad de un melancólico epígono de «otras formas narrativas» a la sombra de la picaresca ${ }^{7}$, se escriben estudios en profundidad, como el de Jean-Michel Laspèras (1987); o manuales compactos, pero sólidos, como el de Isabel Colón (2001). No era posible, ciertamente, evitar incluir sus obras y sus autores (teniendo en cuenta el insoslayable referente de Cervantes

7 Véase Vállo (1983: 449-528). Lo mismo en el suplemento 3/1, editado por Egido (1992: 252299). Ferreras (1987: 35-45) incluirá en su breve estudio La novela del siglo XVII el mínimo capítulo «La novela corta, o cervantina». 
o de la frondosa picaresca) en el incómodo reducto de los menores o los epígonos. Ese reducto del que la historiografía literaria sólo parece esperar «la continuidad pragmática» o la «alteridad delicuescente» ${ }^{8}$. Pero allí era donde precisamente había que indagar. Porque a ese callejón sin salida había llevado tal vez la conocida indigencia en la que el pesimista y disolutivo diagnóstico del maestro José $\mathrm{F}$. Montesinos había situado, en 1955, la novela; es conocido pero merece la pena recordarlo:

La novela se le escapa a España literalmente de las manos. [...] En la Península, dos enormes rémoras se oponen a sus progresos [...] Preocupaciones morales que la desvirtúan y falsean, y la boga de un estilo de prosa, el menos apto para la narración y el diálogo que pueda imaginarse. En el campo de la novela corta, más cultivada que la larga en toda aquella centuria, podemos documentar a cada paso la propagación de una mortal flora parásita de moralidades, avisos, condenaciones, discreteos, figuras, ringorrangos y floripondios de todas clases. Me parece advertir otro fenómeno [...]: que el interés por la realidad circundante, supeditado siempre a lecciones morales, vaya adentrándose más y más, y que ello coincida con una especie de involución del género: los autores, olvidados de Cervantes, parecen volver los ojos a Bandello, a Giraldi Cintio, allí donde menos novelescos eran y más parecían serlo, donde se mostraban más atentos a una fabulación vertiginosa y menos al estudio de las circunstancias que los rodeaban (Montesinos 1955: 2-3). ${ }^{9}$

Creo que es la necesidad de acreditar (o refutar) este juicio lo que da sentido a los intentos de análisis más objetivo — no neciamente reivindicador — que se suceden, como ya he dicho, en los últimos veinticinco años del siglo xx. Para ello se haría urgente el acceso a los propios textos, la preocupación por poner en limpio autores - relevantes o no - de una narrativa a la que apenas se le dejaba respirar por entre las costuras del brillante taller ofrecido por Cervantes y Lope. La elección de mi tesis - lo comprendo ahora - hubiera sido imposible sin la lectura de las novelas de María de Zayas, casi heroicamente editadas en una colección de bolsillo por María Martínez del Portal (1973). Menos de un lustro después, Richard F. Glenn y Francis G. Very (1977) publicarían la Sala de recreación de Castillo Solórzano. Desde entonces, y entre siglos, se sucederían algunas ediciones ya mencionadas o que volvieron a los ensayos previos a Cervantes, como la colección Noches de invierno (1609) de Antonio de Eslava, que estudió Julia Barella (1986). Antonella Prato (1988) nos ofrecía por las mismas fechas las Navidades de Madrid y noches entretenidas de Mariana de Carvajal, y su rescate proseguiría

$8 \quad$ Así lo explica, a propósito de los autores de poesía, Lara Garrido (1993: 521) en «Prospectiva sobre los 'Menores' en el Barroco literario español».

9 Bajo este paradigma Barrero Pérez (1990: 27-38) analizaría casi cuatro décadas después novelas de mayor extensión. 
en la atenta edición de Catherine Soriano (1993); en 1989 se publica completa la recopilación de Pedro Castro y Añaya, Auroras de Diana, por parte de María Josefa Díez de Revenga (1989); Luigi Guliani (1992) edita poco después (todavía en una «Biblioteca de clásicos y raros») los Sucesos y prodigios de amor de Juan Pérez de Montalbán; menudean las ediciones, completas o parciales de la siempre fascinante María de Zayas ${ }^{10}$; amén de las privilegiadas Novelas ejemplares de Cervantes (quien ya las había insertado en su Quijote, arranque de la definitiva novela moderna) y las espléndidas Novelas a Marcia Leonarda, diseminadas por Lope en su propia obra poética, han sido revisitadas en impecables ediciones por Julia Barella (2003) y Marco Pressoto (2007).

Sin pretender, claro está, una nómina exhaustiva no puedo sino destacar la sólida antología de Novelas cortas del siglo XVII realizada por Rafael Bonilla Cerezo $(2010)^{11}$, que marca definitivamente el rumbo de un género al que ya no es posible regatear un canon propio. Lejos de un simple diletantismo posmoderno, la edición nos sitúa ante una filología más abierta, que partiendo de los referentes jerárquicos de calidad, excava estratos insospechados, tomando el pulso a aquellas «alteridades» que los menores pueden aportar en aras de modificar los dos grandes tópicos que los habían marginado. Por una parte, el de la anulación del hilván argumental asfixiado por los bloques retóricos de una prosa que, como aseguraba Montesinos, iba a desembocar en el devastado desierto novelístico del siglo XVIII: algo que debe matizarse con la abundancia de reimpresiones de esta narrativa - a veces como meros cuadernillos añadidos a libros de otra especie - por el librero Alonso y Padilla, de agudo instinto comercial ${ }^{12}$. Por otra, el exceso de énfasis en la moralina que por lo general se desprende de las novelas - algo insoslayable, desde luego - como muestra el pretendido predominio en ellas de una exclusiva ideología aristocrática. Para este segundo caso, cualquiera que lea algunas de las novelas - tan soberbias como escabrosas- de la Zayas o el pasmoso eros fraternal que nos ofrece Guevara, se preguntará dónde andaba el censor de turno cuando dio la venia a su impresión. Para lo primero Bonilla nos ofrece, con su nueva apelación a la novela culta que algunos escritores refundan a partir del modelo lingüístico (pero también de fabulación bucólica del Polifemo o las Soledades de Góngora), la posibilidad de renovación del canon haciéndole avanzar justamente por la senda de la retórica tanto para el contar como para el describir (López Grigera 1981: 347-358). Pero también recuerda que el sesgo costumbrista y de estilo llano se aliña con la extravagancia, con la truculencia inverosímil y cuasi

10 Véanse, por ejemplo, los Desengaños amorosos editados por Yllera (1983) y la selección de seis de sus novelas realizada por Redondo Goicochea (1989).

11 Le hace justicia la extensa reseña escrita por Fernando Rodríguez Mansilla (2012: 472-481) en Bulletin Hispanique.

12 Véase Ripoll y Rodríguez de la Flor (1991: 75-97). 
fantástica y con los figurones esperpénticos, buscando un destinatario más allá de la élite estamental: en tal sentido, es imprescindible volver a recordar la nobleza decadente y hasta preburguesa que asoma en las Navidades de la Carvajal, subsistiendo entre la pintura y el bordado, lo que justifica estudios como el de Nieves Romero Díaz (2002). Las novelas cortas barrocas, en fin, a la zaga de María de Zayas, Mariana de Carvajal, Leonor de Meneses e incluso de Ana Abarca de Bolea y Mur han prestado lucidos argumentos a los estudios de género ${ }^{13}$.

Y termino volviendo a Etiemble. Al final de aquel ensayo que no alcancé a incluir en la bibliografía de mi tesis, manifestaba su derrota ante una definición concreta de la novela corta: «ubicua, pero inaprehensible; existente, pero sin esencia» (1977: 137). Por estos lares, sin embargo, la cuestión ya se está haciendo más tangible, adquiriendo indiscutible cuerpo de existencia y ocupando su lugar en el teatro de la memoria de un género sobre el que este volumen reúne una nutrida nómina de trabajos de antiguos y recientes colegas en su estudio. Gracias por permitirme asomarme a él en un nuevo — nunca se sabe si el último - retorno. De lo que estoy segura es que, después de más de treinta y cinco años, parece que, afortunadamente, la novela corta del siglo XvII sigue teniendo quien le escriba.

Recibido: 16/09/2014

Aceptado: 25/10/2014

\section{OBRAs CITADAS}

Baquero Goyanes, Mariano (1983). «Comedia y novela en el siglo XVII». Serta Philologica F. Lázaro Carreter. Madrid: Cátedra, vol. II, pp. 13-19.

BARElla, Julia (1994). «Heliodoro y la novela corta del siglo XvII». Cuadernos Hispanoamericanos, 529-30, pp. 203-222.

Barrero Pérez, Óscar (1990). «La decadencia de la novela en el siglo xviI: el ejemplo de Francisco Santos». Anuario de Estudios Filológicos, 13, pp. 27-38.

Bonilla Cerezo, Rafael (ed.) (2010). Novelas cortas del siglo XVII. Madrid: Cátedra.

CARrasco Urgoiti, Soledad (1995). «La voluntad dividida de José Camerino en la trayectoria de la novela morisca». En Luce López Baralt y Francisco Márquez Villanueva (eds.), Erotismo en las letras hispánicas. Aspectos, modos y fronteras, Nueva Revista de Filología Hispánica, 7, pp. 47-69.

Carvajal, Mariana de (1988). Navidades de Madrid y noches entretenidas, Antonella Prato (ed.). Milán: Franco Angelli.

(1993). Navidades de Madrid y noches entretenidas. Catherine Soriano (ed.). Madrid: Comunidad de Madrid.

Castillo Solórzano, Alonso de (1977). Sala de recreación. Richard F. Glenn y Francis G. Very (eds.). Chapell Hill: Estudios de Hispanófila.

13 Véase el estudio y antología de Whitenack y Campbell (2000).

Edad de Oro, XXXIII (2014), pp. 9-20, ISSN: 0212-0429 
Castro y Añaya, Pedro (1989). Auroras de Diana. María Josefa Díez de Revenga (ed.). Murcia: Academia Alfonso X el Sabio.

Colón CAlderón, Isabel (2001). La novela corta en el siglo XVII. Madrid: Ediciones del Laberinto.

Eslava, Antonio de (1986). Noches de invierno. Julia Barella Vigal (ed.). Pamplona: Institución Príncipe de Viana.

EtiEmble, René (1977). Ensayos de literatura verdaderamente general. Madrid: Taurus.

FERreras, Juan Ignacio (1987). La novela del siglo XVII. Madrid: Taurus, pp. 35-45.

ForMICHI, Giovanna (1973). «Saggio sulla bibliografia critica della novella spagnola seicentesca». Lavori Ispanistici, Serie III. Messina/Florencia: Casa Editrice D’Anna, pp. 5-105.

Gallo, Antonella (2003). Virtuosismi retorici barocchi: novelle con lipograma. Florencia: Alinea Editrice, 2003.

GiLlespie, Gerald (1967). «Novella, nouvelle, novela, Short Novel? A Review of Terms». Neophilologus, 51, pp. 117-127.

GonZÁlez de AmezúA, Agustín (1951), «Formación y elementos de la novela cortesana». En Opúsculos histórico-literarios. Madrid: RAE, I, pp. 194-279.

KRÖMER, Wolfram (1979). Formas de la narración breve en las literaturas románicas. Madrid: Gredos.

LARA GARRIDO, José (1993). «Prospectiva sobre los menores en el Barroco literario español». En Giovanni Battista de Cesare y Silvana Serafín (eds.), El Girador. Studi di Letterature Iberiche e Ibero-Americane offerti a Giuseppe Bellini, vol. 2. Roma: Bulzoni, 1993, pp. 517-554.

LASPÉRAS, Jean Michel (1987). La nouvelle en Espagne au Siècle d'Or. Montpellier: Editions du Castillet.

López Grigera, Luisa (1981). «En torno a la descripción en la prosa de los Siglos de Oro». En VV. AA., Homenaje a José Manuel Blecua. Madrid: Gredos, pp. 347-358.

Martínez CAmino, Gonzalo (1976). «La novela corta del Barroco español y la formación de una subjetividad señorial». Bulletin of Hispanic Studies, 73, pp. 33-47.

Montesinos, José F. (1955), Introducción a una historia de la novela en España en el siglo XIX. Madrid: Castalia, 1955.

Morinigo, Marcos (1957). «El teatro como substituto de la novela en el Siglo de Oro». Revista de la Universidad de Buenos Aires, 2, pp. 8-76.

PABST, Walter (1972). La novela corta en la teoría y en la creación literaria. Madrid: Gredos.

Pacheco-Ransanz, Arsenio (1986). «Varia fortuna de la novela corta en España». Revista Canadiense de Estudios Hispánicos, 10, 3, pp. 407-421.

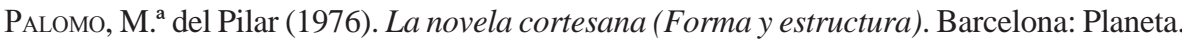

Pérez de Montalbán, Juan (1992). Sucesos y prodigios de amor. Luigi Giuliani (ed.). Barcelona: Montesinos.

RIPoll, Begoña (1991). La novela barroca (1620-1700). Salamanca: Universidad.

Ripoll, Begoña y Fernando R. de la Flor (1991). «Los cien Libros de novelas, cuentos, historias y casos trágicos de Pedro Joseph Alonso y Padilla», Criticón, 51, pp. 75-97.

Rodríguez Cuadros, Evangelina (ed.) (1986). Novelas amorosas de diversos ingenios del siglo XVII. Madrid: Castalia. 
Rodríguez CuAdros, Evangelina (1996). «La novela corta del Barroco español: una tradición compleja y una incierta preceptiva». Monteagudo, $3^{\text {a }}$ época, 1, pp. 27-46.

Rodríguez CuAdros, Evangelina y Marta Haro Cortés eds. (1999). Entre la rueca y la pluma. Novela de mujeres en el Barroco. Madrid: Biblioteca Nueva.

Rodríguez Mansilla, Fernando (2012). «Reseña a Novelas cortas del siglo xVII, ed. Rafael Bonilla Cerezo, Madrid, Cátedra, 2010». Bulletin Hispanique, 114, 1, pp. 472-481.

Romero-DíAz, Nieves (2002). Nueva nobleza, nueva novela: reescribiendo la cultura urbana del Barroco, Newark, Juan de la Cuesta.

TALENS, Jenaro (1977). «Contexto literario y real socializado. El problema del marco narrativo en la novela castellana del seiscientos». En La escritura como teatralidad. Valencia: Universidad, pp. 121-181.

Timoneda, Juan de (1971). El Patrañuelo. Rafael Ferreres (ed.). Madrid: Castalia.

VAíllo, Carlos (1983). «La novela picaresca y otras formas narrativas». En Bruce W. Wardropper (ed.), Historia y crítica de la literatura española. Siglos de Oro. Barcelona: Crítica, pp. 449-528. Recogido también en el suplemento (1992) 3/1, editado por Aurora Egido. Barcelona: Crítica, pp. 252-299.

VEGA, Lope de (2003). Novelas a Marcia Leonarda. Julia Barella Vigal (ed.). Madrid: Biblioteca Nueva, 2003. (2007). Novelas a Marcia Leonarda. Marco Pressoto (ed.). Madrid: Castalia.

Whitenack, Judith A. y Gwyn Elizabeth Campbell (eds.) (2000). Zayas \& her Sisters. An Anthology of «Novelas» by 17th Century Spanish Women. Asheville: Pegassus Press.

Yudin, Florence L. (1966). «Theory and Practice of the Novela Comediesca». Romanische Forchungen, 81, pp. 585-94.

Zabaleta, Juan de (1983). Día de fiesta por la mañana. Cristóbal Cuevas (ed.). Madrid: Castalia.

Zayas, María (1973). Novelas completas. María Martínez del Portal (ed.). Barcelona: Bruguera. (1983). Desengaños amorosos, Alicia Yllera (ed.). Madrid: Cátedra. (1989). Tres novelas amorosas y tres desengaños amorosos. Alicia Redondo Goicochea (ed.). Madrid: Castalia. 
Novela CORTESANA, NOVELA BARROCA, NOVELA CORTA: DE LA INCERTIDUMBRE AL CANON

RESUMEN: El presente artículo pasa revista a las principales aportaciones críticas sobre la novela corta del Barroco (ediciones, monografías y artículos) publicadas desde el último cuarto del siglo xx a la actualidad, subrayando su repercusión y las tareas pendientes a la hora de evaluar un género cada vez más en boga por lo que atañe al Hispanismo y los estudios literarios de la Edad de Oro.

PALABRAS ClAVE: Novela corta, Barroco, Narrativa postcervantina, Novela corta marginada.

Courtly Romance, Baroque Novel, Short Story: from the UnCERTAinty to the Canon

ABSTRACT: This article reviews the main contributions on the novella of the Baroque (editions, monographs and papers) published since the last quarter of the twentieth century to the present, emphasizing its impact and gaps when evaluating this genre, today in vogue with regard to the Hispanism and the Literary Studies of the Golden Age.

Keywords: Short Novel, Baroque, Post-Cervantine Novel, Marginalized Short Novel. 


\section{EDAD DE ORO}

Revista de Filología Hispánica XXXIII

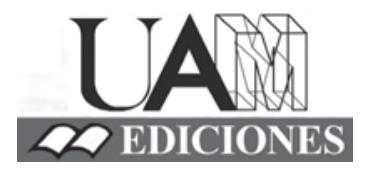




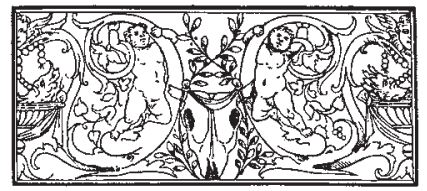

\section{Edad de Oro. Revista de Filología Hispánica}

ISSN: 0212-0429

Dirección:

Teodosio Fernández

Secretaría y edición:

José Ramón Trujillo

Coordinador del volumen XXXIII:

Rafael Bonilla Cerezo

Comité científico internacional:

Carlos Alvar (Univ. de Ginebra)

Ignacio Arellano (Univ. de Navarra)

Javier Blasco (Univ. de Valladolid)

Alberto Blecua (UAB)

Jean Canavaggio (Univ. de París X)

Laura Dolfi (Univ. de Turín)

Aurora Egido (Univ. de Zaragoza)

Víctor García de la Concha (RAE)

Luciano García Lorenzo (CSIC)

Joaquín González Cuenca (Univ. de Castilla-

La Mancha)

Agustín de La Granja (Univ. de Granada)

Begoña López Bueno (Univ. de Sevilla)

Michel Moner (Univ. de Toulouse III)

Joan Oleza (Univ. de Valencia)

Alfonso Rey (Univ. de Santiago)

Lina Rodríguez Cacho (Univ. de Salamanca)

Leonardo Romero Tobar (Univ. de Zaragoza)

Aldo Ruffinatto (Univ. de Turín)

Lía Schwartz (City University of New York)
Redacción y admisión de originales:

Teodosio Fernández

Edad de Oro

Departamento de Filología Española

Universidad Autónoma de Madrid

28049 Madrid (España)

Tfno.: +0034 914974090

correo: teodosio.fernandez@uam.es

Distribución, suscripción y venta:

Servicio de Publicaciones de la UAM

Universidad Autónoma de Madrid

28049 Madrid (España)

Intercambio de publicaciones:

Biblioteca de la Facultad de Filosofía y

Letras (UAM)

Universidad Autónoma de Madrid

28049 Madrid (España)

Han colaborado en este volumen:

Departamento de Filología Española (UAM)

Facultad de Filosofía y Letras (UAM)

Proyecto I+D FFI2013-41264-P La novela

corta del siglo XVII: estudio y edición (y II)

Edad de Oro se recoge en las siguientes bases de datos: SCOPUS, MLA Database, HLAS, Latindex, PIO-Periodical Content Index, ISOC, Dialnet, MIAR, ERIH, DICE, Sumaris CBUC, Ulrich's. Se encuentra evaluada en CIRC: A; INRECH: primer cuartil, posición 6 de 50; MIAR difusión ICDS live: 9.977; SCImago Journal \& Country Rank: H Index 2, SJR 0,101, Q4; RESH índice de impacto: 0.162; ERIH: A INT1; Carhus Plus+: B. 
Evangelina Rodríguez Cuadros (Universitat de València)

Novela cortesana, novela barroca, novela corta: de la incertidumbre al canon 9

Mita Valvassori (Universidad de Los Lagos)

El modelo narrativo del Decamerón en la Edad de Oro: una vieja historia .21

Antonio Gargano (Università degli Studi di Napoli Federico II)

«Difficile est proprie communia dicere»: el género de la novella entre

Boccaccio y Cervantes

Guillermo Carrascón (Università degli Studi di Torino)

Apuntes para un estudio de la presencia de Bandello en la

novela corta del siglo XVII

Leonardo Coppola (Università degli Studi «G. d'Annunzio» di Chieti-Pescara)

La proyección de Straparola en la novela española del Siglo de Oro desde una perspectiva editorial

Mireia Aldomà García

Didactismo, género literario y lector en Giraldi Cinzio

María Jesús Zamora (Universidad Autónoma de Madrid)

«...En tiempo menos discreto que el de agora, aunque de hombres más sabios, se

llamaban a las novelas cuentos». La novela corta y el cuento en el Siglo de Oro......109

Marcial Rubio (Università degli Studi «G. d'Annunzio» di Chieti-Pescara)

La contribución de Cervantes a la novela barroca: la ejemplaridad.

Pierre Darnis (Université Bordeaux Montaigne)

La fuerza de la sangre, La ilustre fregona $y$ Las dos doncellas: ¿tres tipos

folclóricos?

María Soledad Arredondo (Universidad Complutense de Madrid)

De La gitanilla a La sabia Flora malsabidilla. El género, el personaje

y el matrimonio

Antonella Gallo (Università degli Studi di Verona)

Fabulaciones en equívocos burlescos: la Chrónica del monstro imaginado (1615)

de Alonso de Ledesma y novela corta barroca

David González Ramírez (Universidad de Málaga)

El filósofo del aldea (1625) de Baltasar Mateo Velázquez: recepción textual

e hipótesis autorial.

JONATHAN BRADBURY (University of Exeter)

La narrativa breve en la miscelánea del siglo XVII... 
Cristina Castillo Martínez (Universidad de Jaén)

«La fuente del desengaño»: de las Noches de invierno de Eslava a la Tercera

Diana de Tejeda.

MARÍA Zerari (Université Paris-Sorbonne, CLEA)

Furor in fabula: La cruel aragonesa de Castillo Solórzano (o de la dama monstruo).. 241

Giulia Giorgi (Università degli Studi di Ferrara)

Alonso de Castillo Solórzano reescritor de sí mismo: algunas notas sobre los

Escarmientos de amor moralizados y el Lisardo enamorado .257

Angela Fabris (Alpen-Adria-Universität Klagenfurt)

El diálogo con el público y los espacios reales y de maravilla en

Casos prodigiosos y cueva encantada de Juan de Piña 267

María Rocío LePe García (IES San Sebastián, Huelva)

La traducción inglesa de Hipólito y Aminta: una adaptación

con fines comerciales 281

Andrea Bresadola (Università degli Studi di Udine)

La novela española en la Italia del siglo XVII: el caso de Il Feniso

de Francisco de Quintana.

José Teruel (Universidad Autónoma de Madrid)

El triunfo del Desengaño. Marco y desengaño postrero de la Parte segunda

del Sarao y entretenimiento honesto, de María de Zayas

Nieves Romero-Díaz (Mount Holyoke College)

Lecturas alternativas en la Novela del fin bueno en mal principio

de doña Ana Francisca Abarca de Bolea....

Shifra Armon (University of Florida)

Compromiso y distanciamiento en La Venus de Ferrara

de Mariana de Carvajal Saavedra

Mechthild Albert (Rheinische Friedrich-Wilhelms-Universität Bonn)

Las "noches": un subgénero novelístico en perspectiva comparada.... .365

Fernando Copello Jouanchin (Université du Maine, Le Mans)

El mueble en la novela corta del Siglo de Oro: algunas reflexiones

en torno a la cama

Ilaria Resta (Università del Salento):

De la novella al entremés pasando por la novela corta: reescrituras del cuento

La gara delle tre mogli del Cieco di Ferrara. 